\title{
Intervention for ADHD Child using the Montessori Method and ICTs.
}

\author{
https://doi.org/10.3991/ijes.v6i2.8729 \\ Eugenia G. Gkeka( $₫)$, Athanasia Gougoudi, Louisa Mertsioti, Athanasios S. Drigas \\ National Centre of Scientific Research "Demokritos", Athens, Greece \\ eugkeka@yahoo.gr
}

\begin{abstract}
This article intends to address intervention strategies for children with Attention Deficit Disorder (ADHD), with reference to aspects of the Montessori Method, combined with ICTs. Furthermore, new technologies, based on the Montessori philosophy (such as robotics) address behavioral as well as multisensory approaches to ADHD using the senses of vision, hear and touch. In addition, these interventions can also contribute to regulate the child's socialemotional adjustment and learning engagement. Multiple intervention strategies implemented within home and school environment can be effective for students with ADHD.
\end{abstract}

Keywords-Attention Deficit Disorder, ICTs, intervention, Montessori Method

\section{Introduction}

\subsection{Background}

The aim of this article is to present a review of the recent scientific research papers, which introduce the conversation for implementing effective intervention strategies at school and family in context to children with ADHD. The child's family and school environment can beneficially utilize Information Computer technology (ICTs) or Montessori's system in order to implement these strategies. Home-school communication is required. In this paper, four chapters are included related to intervention for children with ADHD, suggesting behavioral as well as sensorial approaches (the tactile and motor, the auditory and the visual one).

Pandria et al., defines the term Attention Deficit Disorder (ADHD) as a psychiatric, mental, neurobehavioral and psychological disorder. It is characterized by developmentally incompatible, pervasive and persistent symptoms of inattention, hyperactivity and impulsivity that are present in two or more environments for more than six months. In addition, the researches describe Neurofeedback as a promising, nonpharmacological therapy for children with ADHD. It is a brainwave biofeedback method based on operant learning. It regulates brain towards homeostasis resulting in optimal network stability while also maintaining flexibility. The WHAAM application provides a framework for counting and measuring behavior parameters related to 
ADHD. The study evaluates the effect of Neurofeedback on ADHD behaviors using the WHAAM application on data gathering [1].

Hoseinpoor et al., study the effect of education through the Montessori Method on attention and social growth of 5-6yrs pre-school children in the city of Isfahan. Attention is a cognitive process in which mind concentration is accumulated on particular environment stimuli. One of the most crucial factors in the Montessori Method is paying attention to inclinations and willingness of children in the primary stages of education [2].

Larson cites principles and procedures of the Montessori Method. Maria Montessori saw that children stay concentrated long enough if they are interested in the materials they are working with. The Montessori Method will benefit children in the following ways: a) Building concentration skills and an active mind: children working as if the teacher does not exist will lead them to identify errors on their own and correct themselves. b) Perspective of the world: Montessori sensorial materials demonstrate attributes of objects (volume, length, temperature, color). c) Build Self-esteem: By working on their own children will realize that they are able to succeed at difficult tasks if they try long enough. d) Social skills: By acting towards each other with 'grace and courtesy' they will begin to consider a Montessori classroom as a social environment [3].

Householders conducted an analysis of the relationship between the Special Education inclusion and Montessori education. Inclusion in Special Education means the placement of a child with special needs in a regular classroom. Montessori itself is one of the first special educators. Both typical students as well as students with learning disabilities [4] considered Montessori practices as effective educational methodologies.

Cossentino cites are Montessori environments where children are free to move, free to choose activities and spend periods of deep concentration. In Montessori classrooms, attention related incidents are less than average, so this pedagogy could be a strategy for treating ADHD. Montessori meets the children requirements and it is the one where differential instruction is happening at the highest level [5].

Bate considers the inter-relationships between teachers' pedagogical beliefs and teachers' beliefs about ICT, is within the socio-cultural environment in which they operate. One of the interviewees, a teacher in a Montessori school, operated in adequate technological environment and was supported by his school. He saw ICT as a vehicle which allows to respond to the variety of student learning styles inhabited in the classroom. His pedagogical beliefs, and beliefs about ICT are aligned and he is constantly looking for ways in which to transform his teaching through ICT. The Montessori ethos of students taking responsibility on their own learning in a supportive environment provided an ideal setting for this teacher to integrate ICT [6].

This analysis [7] defines the quality of Authentic Montessori education. The Montessori teacher can assess a student's needs and provide opportunities to respond to them. In the field of learning differences, the Montessori approach is an effective way to help students to deal with them. For a student with ADHD, working within boundaries addresses their needs. The addition of technology in the classroom has provided 
the Montessori classroom with tools for every child, which can also assist students with learning differences.

\section{Behavioral Approaches}

\subsection{Behavioral Approach and Materials}

Spachos et al., refer to WHAAM mobile application, which provides teachers, parents and health experts a tool to monitor behaviors. People who have a role in the care of a child with ADHD use technology to create a network and develop a behavioral intervention plan. The network gathers data of the child's behavior and plans, with the help of a specialist, alongwith an intervention to reduce the inappropriate behavior or to replace it with a positive one. The application also identifies strategies in which ICTs support multimodal interventions for ADHD [8].

Mooij and Smeets address the question 'How mainstream primary schools can support pupils' with Emotional, Behavioral Disorder (EBD) in practice. A common type of EBD concerned disorders, includes aggression, antisocial behavior, defiance, impulsivity, and hyperactivity; early detection and immediate intervention at home and at school, is critical for children with EBD. There are three important conditions: the school environment, the detection and intervention system, and the availability of support for teachers and schools. The above can be promoted by using ICT developed to support pedagogical-didactic information, flexible grouping of pupils, and adequate handling of instruction and learning in some primary schools. It also includes diagnostic social-emotional and behavioral tests. A general pedagogical-didactic structure and relevant ICT can support various types of learning activities to deal adequately with EBD [9].

Haines notes that according to Maria Montessori learning disorders (such as ADHD, Dyslexia, Dysgraphia) or disruptive behavior disorders, are all forms of wrong functioning. Some are congenital and not much can be done, but those who come from wrong functioning can be addressed by improving the living conditions. Today parents let their toddlers watch TV, whereas a study from the American Academy of Pediatrics indicates that watching videos at that age may lead to ADHD in later life because the brain is rewired. Montessori said that a harmonious-and not so destructive- interaction with environment, contact with nature and handicrafts for older children bring normalization to life, which means living peacefully. In addition, it is the remedy for deviations of modern childhood [10].

DuPaul et al, describes effective school-based intervention strategies. Selfregulation interventions encourage students with ADHD to monitor, evaluate, and reinforce their own behaviors, often in conjunction with the successful applications of teacher-mediated behavioral approaches. Academic interventions can also be delivered through computer technology and classroom peers. Computer assisted instructions in maths and reading, leads to significant improvements on task behavior and academic performance for students with ADHD relative to written seatwork condi- 
tions. A daily report card system is an effective home-school communication program [11].

Riffel analyses the Positive Behavior Interventions and Supports students with ADHD (PBIS). It is all about seeing the behavior with a different eye; praise the desirable ones, and not pointing out the undesirable ones. There are interventions for every aspect of a student's life: Proprioceptive input (air filled cushion, rocking chair, clay or velcro under the desk for the fingers), Behavioral Techniques (secret signal with the student to seek his attention), Organization Skills (colors for subjects, maps) Cool Down (by showing compassion), Self-Esteem (Public relations, Power, Proficiency, Philanthropie), Learning Disabilities (Methods that help learning, discussion groups, demonstrations, practice by doing). [12].

According to Perez and Salinas, the Montessori Method develops executive functions because it encourages self-discipline and independence. The researchers review programs aim to bring improvements in ADHD children's adjustment into school, by training them in cognitive and emotional skills. Such programs are: Cogmed Working Memory Training, which is a computer program designed to improve working memory through intensive, systematic training. The Tools of Mind program (TOOLS), based on Vygotsky (1978). Students learn mathematics, language skills and are trained in Executive Functions (attention, memory and self-regulation) through role-playing. These characteristics are emerged from the Montessori Method. The PATHS program as well as CSRP program (Chicago Readiness Project) both focus on self-regulation and management of feelings [13].

\section{Sensorial Approaches}

\subsection{Tactile - Motor Approach and Materials}

Akabor is focused on finding inclusive pedagogical practices in the Montessori classroom. The Montessori Method is essentially a learner-led pedagogy in a class environment filled with stimulating and tactile materials. It consists of learners of three-year developmental age groups, namely 3-6, 6-9 and 9-12 years. The Montessori classroom allows learners with ADHD to focus on tasks by providing them with predetermined quiet areas, which is away from stressful classroom situations [14].

Jamieson determines the most appropriate intervention strategies used for learning disabilities. Students with attention problems may not focus when a lesson is being presented. They have a short attention span, can be easily distracted, may have poor concentration abilities and have trouble with short-term memory tasks. These children may also be hyperactive or impulsive. They often face problems with their socialization as well. The pivotal aspects of the Montessori theory are the absorbent minds (36 years), the sensitive periods, the prepared environment and the learning materials. Completing and repeating will help children to develop their powers of concentration and for Montessori, concentration is the key to all learning. To aid the development of concentration and attention, some children will need access to a quiet place to work. 
As it refers to materials, the mechanism through which perceptual-motor training methods work, develop children's capacity to concentrate [15].

Virnes focused on the children's actions with educational robotics and investigated the types of encounters between educational robotics and children. Educational robotics refers to any robot technology that is applied to education, in order to learn about it. Some of the other variants used in the construction kit are - Topobo, and the social robot, RUBI which are a progression of traditional toys. Social robots can assist in the education and rehabilitation of children with social and cognitive disorders and other disabilities. In the research environment, all the children in the group were diagnosed with various learning disabilities including Attention Deficit Hyperactivity Disorder (ADHD). In this case, children with limited attention skills worked with the educational robotics during the entire duration of the workshop without requiring breaks. The results indicate the potential of the robots as a learning tool in special needs education, such as traditional toys, which played an important role in Montessori education. These are based on intervention play, discovery and knowledge construction [16].

Parkes et al conducted a research about the Topobo system, a 3D tangible construction kit with the ability to record and playback motion. Educators used it over extended periods in their day-to-day work. Jane, a science teacher at a Montessori school, used Topobo in her 4 th and 7 th grade science classes for 8 months. Topobo engaged the attention of her students throughout, particularly with a student who usually displayed attention disorder issues in extended exercises. Mary, an educational researcher, worked with two groups: one group aged 8-14 with mixed disabilities including ADHD and Asperger's syndrome, the second, a group of kindergarten school children (non-special needs) ages 4-6. Both groups of children expressed immediate attraction to Topobo and they engaged with it for long periods (up to an hour), something very unusual for both populations. In all contexts, Topobo was regarded as a useful and provocative tool, and the idea of constructive learning or self-discovery came through in every context [17].

Ackerman, teacher in a public Montessori school, established a movement shelf in her classroom and observed students' behavior for three months. The shelf provided prepared movement lessons such as yoga cards, hopping lessons, or jumping a rope. Students would have the chance to choose one of the movement lessons during a work period, therefore they had short-time energetic breaks between lessons. The aim was to decrease the disruptive behavior and to increase concentration and self- discipline. Yoga strongly benefits students with ADHD, as it lessens attention problems in the classroom and helps students with social, emotional, behavioral and academic needs. The conclusion was that children enjoyed movement in the classroom, and the movement shelf made a huge difference in the environment of the classroom [18].

The research team Wang et al, examined the impact of the tangible user interface (TUI) on the students learning experience. Direct manipulation makes the touch screen attractive to users and significantly affects students learning processes by stimulating motivation, increasing engagement, and facilitating collaboration. TUI may be one of the primary factors contributing to the enhanced engagement of young learners, students with learning disabilities, and novice computer users. Additionally, re- 
searchers have discussed the potential benefits to help learners with special education needs [19].

\subsection{Visual Approach}

Zuckermann et al introduced digital Montessori-inspired manipulatives (MiM).They are computationally enhanced manipulatives designed to help children understand abstract concepts. Accessible materials increase the learning capacity in people with learning disabilities. Two Digital Manipulatives are presented: the Flowblocks Digital MiM- a set of connected blocks with a light representing the dynamic process. Children become familiar with counting, probability, looping, branching. The System Blocks Digital MiM is a physical construction Kit. Blocks represent different paradigms from real life (water flow through bathtub, bank account savings growth from interest rate, $\mathrm{CO} 2$ pollution growth from emissions). Children come across dynamic methods and concepts such as rates, accumulation, negative feedback and positive feedback [20].

Weisberg et al., argues that Tangiplan is a set of tangible connected objects that represents tasks children perform during their morning routine. The goal is to make objects to become reminders and facilitate organization and time management for ADHD children. Objects are pyramid shaped, with LED lights inside. They are placed where the tasks are supposed to be performed (e.g by the sink where brushing of the teethis done or inside a shoe). Objects are location specific and location enhances cognitive processes like memory and learning. When time elapses, white light flows across the front cover from top to bottom, whereas, when time is up, red light will begin to flow. The daily progress is written down in a document with four columns: number/ name of task/ time per task and remarks [21].

Luiselli and Fischer present the following technological applications for individuals with ADHD:1) Tests such as CPT3 (Conners Performance Test,3rd Edition) or TOVA (Test of variable performance) Both these tests are run on a computer. The tests measure one's attention, distractibility as well as speed and accuracy in response to visual stimuli. 2) The area of virtual reality video games (Microsoft Kinect, Nintendo Wii) allows a person to watch himself/herself interacting with the video, and, possibly, reduces his excessive movement behavior.3) Computers in the classroom present material in more adaptive ways. Programs assist with outlining, brainstorming and mind mapping, all of which improves organizing and flow of writing, necessary for ADHD students. 4)3D imaging and 3D printing capability provides virtual environments as a classroom-learning tool. VE classrooms offer new models of learning (e.g. haptic gloves, spatial manipulation, person machine interaction, etc.) that could be helpful to those with learning challenges [22].

Pegrum et al., report on the adoption of mobile handheld technologies in ten Western Australian independent schools, based on interviews with the staff, conducted in 2011. These devices lead to an expansion of the spaces and times of learning. Furthermore, ICTs can support a range of pedagogical approaches; however, they are suited for the promotion of social constructivism and related active, collaborative, student-centered approaches, like the Montessori. There are also particular benefits 
for students with special needs, including students who require early intervention or those who are struggling with the curriculum [23].

Yusof et al conducted a study to investigate teachers' perception of m-learning (mobile learning) in the special education classes. Ten special education teachers from four schools were interviewed. The results are as follows: Teachers need to learn the applications. The applications may meet each student's different educational needs (with fun) and offer teachers different methods, which can secure special needs students' attention. Edutainment (education-entertainment) benefits students with ADHD; their attention is engaged at the same time they can learn [24].

\subsection{Auditory Approach}

Berger and Scheck analyze music's basic elements (such as rhythm, pulse, melody) and why music can be a therapeutic tool. Rhythm: periodicity or rhythm is everywhere on the planet. The close relationship between physiologic rhythms makes the latter very effective in capturing one's attention. Pulse coupled with pace are timekeepers and controllers of a piece of music, and consequently, of body movement. Pulsed rhythms applied to children with autism and behavior problems help them to become organized and paced. Melody: it goes beyond words in expressing feelings. Many ADHD children exposed to constant music therapy interventions have learned to wait and attend, because music provided them the motivation to wait until the end [25].

James, a teacher in a private school, held a study about how music helps in establishing a peaceful classroom environment. The author refers to previous studies, which presented the combination of music and Montessori philosophy as a basis for a "peaceable schools framework". The participants were 16 students between first and third grade. The students had needs from high functioning autism, selective mutism, anxiety and ADHD. The teacher considered 'clean up time' as a reflection of the sense of community. Children were taught songs from the Beatles and after that, they were seen singing daily. After six weeks, children had a clear understanding of the words 'cooperation' and 'community'. They became helpful towards each other and more responsible during the clean-up time [26].

In this study [27], 200 Montessori students aged 3-5 years-old were divided into two groups. The results showed that students who received music enriched Montessori instructions had significantly higher math scores, and that the 3 year-old students had higher scores than the 4 year-old or 5 year-old children. This study shows that an arts-rich curriculum had a significant positive effect on young students' overall academic achievement. Music was also being used in the treatment of Attention Deficit Hyperactivity Disorder (ADHD). Montessori programs could include daily group 'music and movement' sessions, enhanced with weekly piano lessons, to provide the child with every opportunity to develop his whole being. The introduction of modern technology has opened a window for music instruction.

Dr. Tomatis was a French Medical doctor with an ENT (Ear, Nose and Throat) specialization. He developed a machine called 'electronic ear' in order to train two muscles - by music or voice and conceived a test to know how the functions of the 
ears were used. The Tomatis method can greatly improve the life of many autistic and ADHD children. These children are hypersensitive towards sounds. This happens because they listen predominately with their bodies instead of their ears. Sounds picked up by the body go directly to the brain, without being filtered. The Tomatis method can help these children reconnect with their families and environment by reducing hypersensivity and regulating sensory integration, allowing them to move outside their protective shells. The Tomatis Listening Program focuses on listening to vocal exercises using Mozart and Gregorio Chants. The method has been tested rigorously and was found to be very effective in the treatment of learning difficulties and learning problems [28].

Schaub submitted this research, in order to define the effects of mindfulness practices and activities on student attention and work engagement. The 5-week study incorporated breathing and visualization exercises and involved children between ages of 9 and 12 years in a private Montessori school. Mindfulness research has noted an increased ability to control attention, and reduce the automatic responses, which tend to be symptoms of students with ADHD. Dr. Montessori's research showed that even young children have the ability to focus their attention on meaningful work. She also believed that children would be thoughtful and mindful in their actions with the support of a loving adult [29].

\section{Conclusion}

The paper examines the significant role of Technology as a tool providing alternative ways of learning for ADHD students. The impact of Montessori philosophy in the current technological applications is profound. Electronic devices based on Montessori materials; aim to build student's attention, while computer programs and mobile devices offer multisensory ways of learning. The fundamental principles of the Montessori Method such as 'freedom within limits', the respect towards each individual's abilities and needs, and the encouraging courteous environment are timeless values that are beneficial for every child, and not just the students with ADHD. The Montessori Method produces more creative, mature and socially adept children because it focuses on personal development. Movement in the classroom helps students to focus for longer periods of time, lessens behavioral problems, and improves overall physical, social and cognitive skills. To sum up, it is a philosophy, which is 100 years old and is balanced with a cutting-edge technology in order to meet the special educational needs meaningfully.

\section{$5 \quad$ References}

[1] Pandria, Niki, Dimitris Spachos and Panagiotis d. Pamidis "Evaluation Neurofeedback on ADHD using Mobile Health technologies". XIV Mediterranean Conference on Medical and Biological Engineering and Computing .Springer, Cham.2016 
Paper-Intervention for ADHD Child using the Montessori Method and ICTs

[2] Spachos, Dimitris, et al. "WHAAM: A mobile application for ubiquitous monitoring of ADHD behaviors." Interactive Mobile Communication Technologies and Learning (IMCL), 2014 International Conference on. IEEE, 2014.

[3] Hoseinpoor, Masume, Mozhgan Arefi, and Saeed Sadeghi. "Study of Effect of Education through the Montessori Method on Attention and Perceptual Organization and Social Growth of 5-6yr Preschool Children in the City of Isfahan." DOI: https://doi.org/10.1109/IMCTL.2014.7011153

[4] Larson, Heike. "The Montessori method: educating children for a lifetime of learning and happiness." Object Stand 5.2 (2010): 41.

[5] Montessori, Maria. "Inclusion in the Classroom Nicole Householder St. Catherine's University Analysis of Contemporary Issues EDU 6210."

[6] Cossentino, Jacqueline. "Following all the children: Early intervention and Montessori." Montessori Life 22.4 (2010): 38-45.

[7] Bate, Frank. "The role of ICT in the pedagogical transformation of primary teachers: Dream, aspiration, reality." EdMedia: World Conference on Educational Media and Technology. Association for the Advancement of Computing in Education (AACE), 2010.

[8] Andrew, Sandra Wyner. "The Teacher For The Authentic Montessori Experience Michelle A. Aldrich St. Catherine's University EDUC 6210-Analysis of Contemporary Issues in Education and Montessori." (2014).

[9] Mooij, Ton, and Ed Smeets. "Towards systemic support of pupils with emotional and behavioural disorders." International Journal of Inclusive Education 13.6 (2009): 597-616.

[10] Haines, Annette. "Montessori: Now More Than Ever."

[11] DuPaul, George J., Lisa L. Weyandt, and Grace M. Janusis. "ADHD in the classroom: Effective intervention strategies." Theory into Practice 50.1 (2011): 35-42. DOI: https://doi.org/10.1080/00405841.2011.534935

[12] Riffel, Laura A. "Non-Medicated Interventions for Learners with Attention Deficit Hyperactive Disorder (ADHD)."

[13] Sánchez Pérez, Noelia, and Carmen González-Salinas. "School adjustment of pupils with ADHD: cognitive, emotional and temperament risk factors." (2013).

[14] Akabor, Shakira. Inclusive pedagogical practices found in a Montessori primary classroom: a case study in Gauteng. Diss. 2015.

[15] Jamieson, Natalie. The contribution of the Montessori approach to multisensory approaches to early learning disabilities. Diss. 2006

[16] Virnes, Marjo. "Four Seasons of Educational Robotics."

[17] Parkes, Amanda J., Hayes Solos Raffle, and Hiroshi Ishii. "Topobo in the wild: longitudinal evaluations of educators appropriating a tangible interface." Proceedings of the SIGCHI Conference on Human Factors in Computing Systems. ACM, 2008. DOI: https://doi.org/10.1145/1357054.1357232

[18] Akkerman, Abby. Benefits of Movement in a Montessori Classroom on Children's Behavior and Focus. Diss. University of Wisconsin-River Falls, 2014.

[19] Wang, Tianchong, Dave Towey, and Morris SY Jong. "Exploring young students' learning experiences with the iPad: a comparative study in Hong Kong international primary schools." Universal Access in the Information Society 15.3 (2016): 359-367. DOI: https://doi.org/10.1007/s10209-014-0395-7

[20] Zuckerman, Oren, Saeed Arida, and Mitchel Resnick. "Extending tangible interfaces for education: digital montessori-inspired manipulatives." Proceedings of the SIGCHI conference on Human factors in computing systems. ACM, 2005. DOI: https://doi.org/10.1145/1054972.1055093 
Paper-Intervention for ADHD Child using the Montessori Method and ICTs

[21] Weisberg, Orad, et al. "TangiPlan: designing an assistive technology to enhance executive functioning among children with adhd." Proceedings of the 2014 conference on Interaction design and children. ACM, 2014. DOI: https://doi.org/10.1145/2593968.2610475

[22] Luiselli, James K., and Aaron J. Fischer, eds. Computer-assisted and web-based innovations in psychology, special education, and health. Academic Press, 2016.

[23] Pegrum, Mark, Grace Oakley, and Robert Faulkner. "Schools going mobile: A study of the adoption of mobile handheld technologies in Western Australian independent schools." Australasian Journal of Educational Technology 29.1 (2013).

[24] Mohd Yusof, Anuar, et al. "Teachers' perception of mobile edutainment for special needs learners: the Malaysian case." International Journal of Inclusive Education 18.12 (2014): 1237-1246. DOI: https://doi.org/10.1080/13603116.2014.885595

[25] Berger, Dorita S., and Daniel J. Schneck. "The use of music therapy as a clinical intervention for physiologic functional adaptation." Journal of Scientific Exploration 17.4 (2003): 687-703.

[26] James, Heidi S. "Music, Community, and Cooperation in a Lower Elementary Classroom." (2016).

[27] Harris, Maureen Ann. "Differences in mathematics scores between students who receive traditional Montessori instruction and students who receive music enriched Montessori instruction." Journal for Learning through the Arts 3.1 (2007): 10.

[28] MURASE, Kuniko. "The Tomatis Method Builds a Safer World for The Hearingimpaired Child." (2011).

[29] Schaub, Jamie L. "The Effects of Mindfulness Practices and Activities on Student Attention and Work Engagement in a Multi-age 4th to 6th grade Montessori Classroom." (2016).

\section{Authors}

Eugenia G. Gkeka, Athanasia Gougoudi, Louisa Mertsioti, and Athanasios S. Drigas are with National Centre of Scientific Research "Demokritos", Athens, Greece.

Article submitted 13 April 2018. Final acceptance 22 July 2018. Final version published as submitted by the authors. 